\title{
PREFACE
}

\section{Changing climate and demands for sustainable development}

\author{
Mannava Sivakumar ${ }^{1, *}$, Pierre Bessemoulin ${ }^{2}$, Thomas C. Peterson ${ }^{3}$, Ghassem Asrar ${ }^{1}$ \\ ${ }^{1}$ World Meteorological Organization, 7bis, avenue de la Paix, Case postale No. 2300, 1211 Geneva, Switzerland \\ ${ }^{2}$ Formerly: Météo-France, Paris, France \\ ${ }^{3}$ National Climatic Data Center, NOAA, Federal Building, 151 Patton Avenue, Asheville, North Carolina 28801-5001, USA
}

\begin{abstract}
In order to meet the multi-faceted challenges of climate variability and climate change, there is a need for wise and well-informed decision-making at every level. Those who make these decisions require the best possible climate science and information. The 14 articles in this CR Special represent a synthesis of the requirements of society for climate information, products and services to support adaptation to climate variability and change, as well as for sustainable development.
\end{abstract}

KEY WORDS: Climate change $\cdot$ Sustainable development $\cdot$ Climate products and services

Over the last 2 decades, climate change has emerged as one of the most crucial issues for humankind, with serious implications for sustainable development. The WMO/UNEP Intergovernmental Panel on Climate Change (IPCC) in its Fourth Assessment Report confirmed that in the 20th century, the increase in average temperature was $0.74^{\circ} \mathrm{C}$; sea level increased by $17 \mathrm{~cm}$ and a large part of the snow cover in the northern hemisphere vanished. We are also witnessing major precipitation changes in different parts of the world. In temperate regions, precipitation, rainfall and snow have increased, while in areas with tropical, subtropical and Mediterranean climates there has been a decline. But all of this is also accompanied by an increase in the frequency and severity of extreme precipitation events.

Increases in the frequency of droughts and floods are projected to negatively affect local crop production, especially in subsistence sectors at low latitudes. Some regions are more vulnerable than others. SubSaharan Africa, already under a good deal of stress, will be further affected by stress from climate change, and the number of people affected by water stress is projected to increase to 75-250 million by the year 2020. Mega-river deltas (e.g. the Ganges/Brahmaputra, Irrawaddy and Mekong deltas) are extremely vulnerable, and include a number of heavily-populated cities. About half of the world's population live within $200 \mathrm{~km}$ of a coastline, with absolute numbers increasing, and a number of coastal regions are under threat of flooding.

According to the Stern Report, commissioned by the British Government, the economic costs of of the projected changes in climate will be similar to the economic effects of a great depression combined with a world war. But-momentous as the challenge isthe Stern Report concludes that adapting to climate change is both technologically feasible and economically rational. In order to meet the multi-faceted challenges of climate variability and climate change, there is a need for wise and well-informed decision-making at every level from households, communities, countries and regions, to international fora, including the UN Framework Convention on Climate Change. Those decisions will require, directly or indirectly, access to the best possible climate science and information, and 
effective application of this information through climate services. Climate information delivers economic value by providing users whose activities are sensitive to climate conditions with a basis for making decisions. Major research efforts are required to increase the time-range and skill of climate predictions through new research and modelling initiatives, and to improve the observational basis for climate prediction and services, as well as the availability and quality control of climate data.

In the elaboration of climate services for sustainable development, the WMO's Commission for Climatology (CCl) and the World Climate Research Programme (WCRP) - established under the joint sponsorship of the International Council for Science (ICSU), the WMO and the Intergovernmental Oceanographic Commission (IOC) of UNESCO-play a very important role. The vision of the $\mathrm{CCl}$ is to provide world leadership in promoting expertise and international cooperation in climatology. The role of the $\mathrm{CCl}$ is to:

- Promote the development of improved climate products and services for facilitating human activities and sustainable development;

- Coordinate general requirements for observations, collection, supply and exchange of climate data;

- Promote better practices of climate data management including data rescue, and archival and statistical analysis;

- Coordinate and promote the analysis and monitoring of climate and its variability and change;

- Develop and review operational climate information and prediction services;

- Prepare authoritative statements on climate;

- Raise awareness of climate information, applications and services to sectors such as agriculture, water resources and health, and to provide the necessary capacity building tools.

The objectives of WCRP are to determine the predictability of the climate system and to determine the effect of human activities on climate.

In order to respond to the demand for climate services that promote sustainable development in the context of a changing climate, the WMO, together with the WCRP and the Turkish State Meteorological Service (TSMS), organized the technical conference on 'Changing climate and demands for climate services for sustainable development' in Antalya, Turkey, from 16 to 18 February 2010, in collaboration with the 15th Session of the CCl. The conference was co-sponsored by Météo-France.
Specific objectives of the technical conference were to:

- Review the benefits and risks to society from climate variability and change;

- Review the requirements of society for climate information, products and services to support sustainable development and adaptation to climate variability and change;

- Review known gaps in meeting the requirements of the users of climate information (henceforth 'users');

- Identify (within the WMO and its partners) the currently available tools, techniques, infrastructure, systems and human capacity for serving user requirements across a range of climate-information products and services at regional, national and local levels;

- Assess the adequacy of climate products and services to meet societal requirements;

- Review recent advances in climate prediction and projection research, from seasonal to decadal to centennial timescales, to consider their operational uptake and to plan joint $\mathrm{CCl} / \mathrm{WCRP}$ actions to sustain research-operations linkages, particularly at impact level (i.e. regional/national scales); and

- Recommend to the upcoming 15th Session of the $\mathrm{CCl}$, new approaches to improving the contributions of the $\mathrm{CCl}$ and WCRP and other relevant partners.

The Technical Conference was organized in 5 sessions: (1) societal demands for climate services geared towards adaptation and risk management; (2) capabilities for data management, monitoring and assessment; (3) capabilities for climate prediction and projection; (4) partnerships and collaborative activities; (5) climate research achievements and gaps: uptake of user requirements for new research and applying achievements to operations (Special Joint Session with the Joint Scientific Committee (JSC) of WCRP).

The 14 articles in this CR Special represent a synthesis of the requirements of society for climate information, products and services to support adaptation to climate variability and change, as well as for sustainable development. The Special Joint Session with the JSC of the WCRP formulated recommendations to sustain research-operational linkages, and also suggested new approaches to improving the contributions of the $\mathrm{CCl}$ and the WCRP in this regard.

Acknowledgements: We are most grateful to M. Jarraud, the Secretary-General of WMO, and to Mehmet Çaglar, Director General of TSMS and the Permanent Representative of Turkey with WMO for their encouragement and support, and to the authors and the reviewers for their efforts in bringing out this issue on time. 